\title{
Strength and Fatigue Properties of Sandstone under Dynamic Cyclic Loading
}

\author{
Mingming He, Ning Li, Yunsheng Chen, and Caihui Zhu \\ Institute of Geotechnical Engineering, Xian University of Technology, Xian 710048, China \\ Correspondence should be addressed to Mingming He; 807658619@qq.com
}

Received 11 July 2015; Revised 7 September 2015; Accepted 9 September 2015

Academic Editor: Sergio De Rosa

Copyright (C) 2016 Mingming He et al. This is an open access article distributed under the Creative Commons Attribution License, which permits unrestricted use, distribution, and reproduction in any medium, provided the original work is properly cited.

\begin{abstract}
This paper presents an experimental investigation of strength and fatigue properties of intact sandstone samples subjected to dynamic cyclic loading in the laboratory. Tests were conducted on sandstone samples with loading frequencies ranging in 0.5 , 1,2 , and $4 \mathrm{~Hz}$, loading amplitudes of $1,15,30,60,90$, and $120 \mathrm{kN}$, and loading speeds of $0.5,1,2,4$, and $8 \mathrm{kN} / \mathrm{s}$. In this study it was shown that the loading frequency, as well as the amplitude and loading speed, was of great significance and affected the mechanical characteristics of sandstone under dynamic cyclic loading. The fatigue life of sandstone was found to decrease with loading speeds and amplitudes but increase with loading frequencies. It was found that the minimum of the dynamic strength and deformation factor of sandstone was obtained at loading speeds of $2 \mathrm{kN} / \mathrm{s}$ but the maximum at loading frequencies of $1 \mathrm{~Hz}$. Finally, it was concluded that the relationship between the fatigue life and loading speed, frequency, and stress amplitude under dynamic cyclic loading would be expressed as the $S-N$ curve, which showed that the fatigue characteristic of sandstone was similar to that of metal materials.
\end{abstract}

\section{Introduction}

The characteristics of rock and rock masses play a key role in the long-term stability of rock engineering. In order to understand dynamic mechanical properties of rock as engineering materials, it is necessary to start with the behavior of intact rock. In recent, greater attention is focused on the behavior of rock in dynamic cyclic loading under varying loading scenarios. For rock engineering, understanding the strength and fatigue behavior under dynamic conditions is of special interest since the diverse dynamics significantly influence rock characteristics.

The reported literature has shown that there has been some progress in the description of the fatigue behavior of rock and that the study of dynamic mechanical of rock has also been carried out. From the reported literature, it was found that intact and nonjointed samples [1-13] were extremely susceptible to fatigue failure. Some have also investigated the dynamic properties of failed models of jointed rock [14-23]. The following is a summary of work related to dynamic properties of rock specimens in the laboratory. Attewell and Farmer [1] reported that, during cyclic compression tests on rock specimens, the dynamic strength of rock appeared to be reduced by $50-70$ percent of the static strength. Singh $[2,3]$ investigated fatigue and strain hardening behavior of greywacke under cyclic loading. Results show that, at a given maximum stress level, stress amplitude, and loading frequency, the percentage strain hardening increased with number of load cycles. Tien et al. [4] studied deformation and fatigue behaviors of saturated sandstone subjected to cyclic loadings. It was revealed that there existed a critical axial deformation beyond which the failure of rock would occur immediately. Li et al. [5] investigated critical evidence for fatigue crack propagation in sandstone samples. Results indicated that the subcritical crack propagation rate in the sandstone demonstrated a dependence on the range of the stress intensity factor. Bagde et al. [6-9] reported that some of these materials became stronger and more ductile, while others became weaker and more brittle when subjected to dynamic cyclic loads. It was concluded that rock would more readily succumb at low loading frequencies and low amplitude than at high loading frequencies and amplitude. Xiao et al. [10] proposed a damage variable to describe the actual evolution process of granite fatigue damage by analyzing the test results of the uniaxial cyclic dynamic tests. Liu and $\mathrm{He}$ [11] carried out a series of laboratory tests to assess 
the effects of confining pressure on the mechanical properties and fatigue damage evolution of sandstone samples subjected to cyclic loading. Results from the tests indicated that the level of confining pressure had a significant influence on the cyclic deformation and fatigue damage evolution of the sandstone samples tested. Burdine [12] carried out an investigation to assess the cumulative damage to samples under various loading conditions. It was found that the fatigue strength of rock was strongly dependent on its grain size, with fine-grained rocks having higher and more consistent strengths. Zhenyu and Haihong [13] studied the behavior of rock under cyclic loading and proposed an endochronic constitutive equation that had an ability to describe the stress-strain curve under cyclic loading conditions and fit the experimental data well. Eberhardt [14] reported that fracture damage induced through sampling disturbance had a markedly different effect on material strength than damage induced through monotonic or cyclic loading. Lajtai et al. [15] investigated the effect of strain rate on strength for brittle limestone ductile salt rock. The results showed an increase in compressive strength with increasing strain and stressing rate, although the rate effect was very small. Ray et al. [16] reported that during cyclic compression tests on sandstone specimens, fatigue strength and Young's modulus increased with the rise in the strain rate and failure strain increased with increase of the number of cycles. Brown and Hudson [17] studied the fatigue behavior of idealized models of jointed rocks subjected to cyclical loading. Test results showed that the failed models of jointed rock were extremely susceptible to cyclic fatigue failure. Prost [18] investigated the effect of a preexisting joint on initiation and propagation of cracks during cyclic compression-tension tests. It was reported that the largest loads and loading amplitudes generally caused failure in the least number of cycles. Chen and Taylor [1921] presented a nonlocal analysis of the dynamic damage accumulation processes in brittle solids. The results indicated that the model reproduced, qualitatively, the brittle behavior of rock under blasting conditions. Li et al. [22, 23] studied the mechanical characteristics and proposed a fatigue damage model for jointed rock masses and dry, frozen, and saturated sandstone samples subjected to dynamic cyclical loading.

From the reported literature, it is found that earlier studies related to dynamic behavior of rock concentrated mostly on prepared jointed models in laboratory, mathematical model, and so forth. These studies reveal that different rocks show different responses in cyclic loading conditions. While the general mechanicals of rock have been well researched, studies on the effect of the strength and fatigue properties of rock on loading conditions and on the relationship between dynamic strength and static strength of rock are scarce. Understanding how loading condition influences strength and fatigue in rock has a great significance in predicting cyclic fatigue in the coal mines. Therefore, a good understanding of the strength and fatigue characteristics of rock under different scenarios is essential. In this paper, an empirical investigation into the strength and fatigue characteristics of sandstone under different loading conditions is reported. The results are also expected to provide a better understanding of
TABLE 1: Mineral name and its composition.

\begin{tabular}{lc}
\hline Mineral name & Composition (\%) \\
\hline Biotite & 10 \\
Muscovite & 2 \\
Potassium feldspar & 63 \\
Quartz & 19 \\
Metal minerals & 3 \\
Cuttings & 3 \\
\hline
\end{tabular}

the relationship between dynamic strength and static strength of rock in burst prone areas.

\section{Test Scheme and Methods}

2.1. Experimental Equipment. The tests were conducted on a WDT-1500 reactive material testing machine. The WDT-1500 controller consisted of hardware component and software applications. It consists of four main parts: DOLI's digital servo controller, an axial dynamic loading system, a selfbalanced pressure chamber, and a data acquisition system. The hydraulic station provides the power, the computer measurement and control system are used to control the electrichydraulic servo valve, and the host runs the experiment under the control of the computer. The maximum axial force used is $1500 \mathrm{kN}$, the highest confining pressure applied is $80 \mathrm{MPa}$, the highest frequency is $10 \mathrm{~Hz}$, and the highest amplitude is $0.5 \mathrm{~mm}$.

2.2. Experimental Method. To ensure the similarity of the tested samples as much as possible, the sandstone samples with almost the same content of impurity and without cracks were selected. The sandstone samples were cut into circular cylinders $50 \mathrm{~mm}$ diameter $\times 100 \mathrm{~mm}$ length, and the evenness of the head faces was controlled to $0.02 \mathrm{~mm}$ according to the Chinese standard for tests method of engineering rock masses. The samples were prechecked by ultrasonic means with a velocity limit of $3752 \pm 30 \mathrm{~ms}^{-1}$. The tested samples consisted of a wide variety of minerals shown in Table 1 . Therefore, we assumed that the effect on the test results would be minimal.

To investigate the dynamic strength properties of the sandstone samples under different conditions, the sandstone samples were divided into three groups, each subjected to a different cyclic loading scheme and different loading frequencies, different cyclic loading speeds, and different cyclic loading amplitudes. The illustration of loading condition on time-displacement curve throughout the dynamic cyclic loading is given in Figure 1.

\section{Test Results and Analysis}

3.1. Strength and Fatigue Properties of Sandstone under Dynamic Cyclic Loading with Different Loading Speeds. To study the strength and fatigue properties of the sandstone under different speeds of dynamic cyclic loading, the loading amplitude and frequency were up to $30 \mathrm{kN}$ and $1 \mathrm{~Hz}$, 
TABLE 2: Strength and fatigue properties of sandstone under different loading rates.

\begin{tabular}{|c|c|c|c|c|c|}
\hline $\begin{array}{l}\text { Loading amplitude } \\
(\mathrm{kN})\end{array}$ & $\begin{array}{l}\text { Loading frequency } \\
(\mathrm{Hz})\end{array}$ & $\begin{array}{c}\text { Loading speed } \\
(\mathrm{kN} / \mathrm{s})\end{array}$ & $\begin{array}{c}\text { Peak stress } \\
(\mathrm{MPa})\end{array}$ & $\begin{array}{c}\text { Peak strain } \\
(\%)\end{array}$ & $\begin{array}{l}\text { Fatigue life } \\
(N)\end{array}$ \\
\hline 30 & 1 & 0.5 & 83.88 & 1.496 & 277 \\
\hline 30 & 1 & 1 & 83.27 & 1.457 & 138 \\
\hline 30 & 1 & 2 & 81.81 & 1.199 & 68 \\
\hline 30 & 1 & 4 & 91.34 & 1.233 & 39 \\
\hline 30 & 1 & 8 & 99.82 & 1.317 & 18 \\
\hline
\end{tabular}

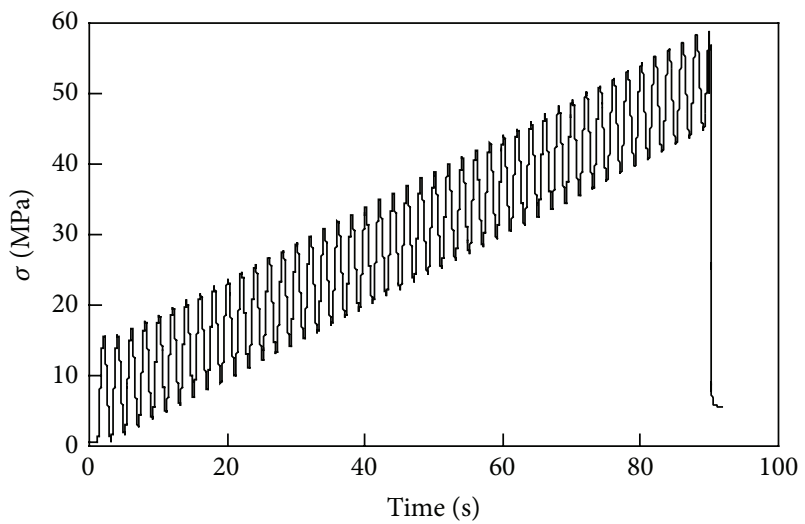

FIgure 1: The curve of stress-time under uniaxial dynamic cyclic loading condition.

respectively. The loading speeds were $0.5 \mathrm{kN} / \mathrm{s}, 1 \mathrm{kN} / \mathrm{s}, 2 \mathrm{kN} / \mathrm{s}$, $4 \mathrm{kN} / \mathrm{s}$, and $8 \mathrm{kN} / \mathrm{s}$. We also performed dynamic cyclic loading tests under loading amplitude of $1 \mathrm{kN}$ with loading speeds of $0.5 \mathrm{kN} / \mathrm{s}, 1 \mathrm{kN} / \mathrm{s}, 2 \mathrm{kN} / \mathrm{s}, 4 \mathrm{kN} / \mathrm{s}$, and $8 \mathrm{kN} / \mathrm{s}$.

The strength and fatigue properties of the sandstone samples are shown in Table 2. The stress-strain and straintime curves of the dynamic uniaxial cyclic loading test under different loading speeds are shown in Figure 2. It was found that the peak stress, peak strain, and fatigue life change notably with the change in loading speed. There is a similar relation between the peak stress and peak strain and the loading speed. At a lower loading speed of $0.5 \mathrm{kN} / \mathrm{s}$, the peak stress and peak strain are not the lowest, while the value of peak stress and peak strain decrease to $81.81 \mathrm{MPa}$ and $1.179 \%$ when the loading speed is $2 \mathrm{kN} / \mathrm{s}$, respectively. As the loading speed increases, the peak stress and peak strain increase when the loading speed is greater than $2 \mathrm{kN} / \mathrm{s}$, while the average fatigue life is reduced obviously. The minimum of the dynamic peak stress and peak strain of the sandstone is obtained at loading speeds of $2 \mathrm{kN} / \mathrm{s}$. This phenomenon may be caused by enhanced crack propagation of the sandstone with increasing loading speed.

In the sandstone testing under loading amplitude of $1 \mathrm{kN}$ with loading speeds of $0.5 \mathrm{kN} / \mathrm{s}, 1 \mathrm{kN} / \mathrm{s}, 2 \mathrm{kN} / \mathrm{s}, 4 \mathrm{kN} / \mathrm{s}$, and $8 \mathrm{kN} / \mathrm{s}$, the average fatigue lives are $2163,1347,558,232$, and 143 , respectively. Thus, decrease of the loading amplitude increases the average fatigue life greatly, mainly because the loading amplitude of $1 \mathrm{kN}$ in each cycle causes less damage to the sample, slowing the crack propagation. When the stress

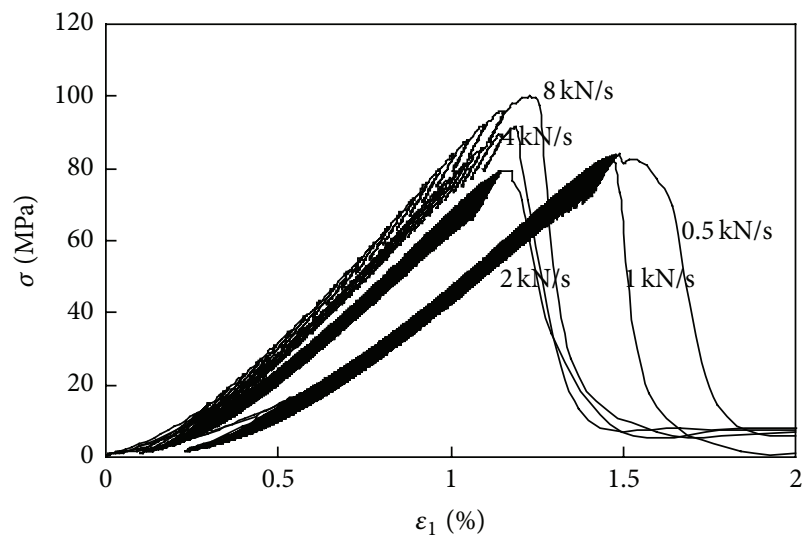

(a) Stress-strain curves

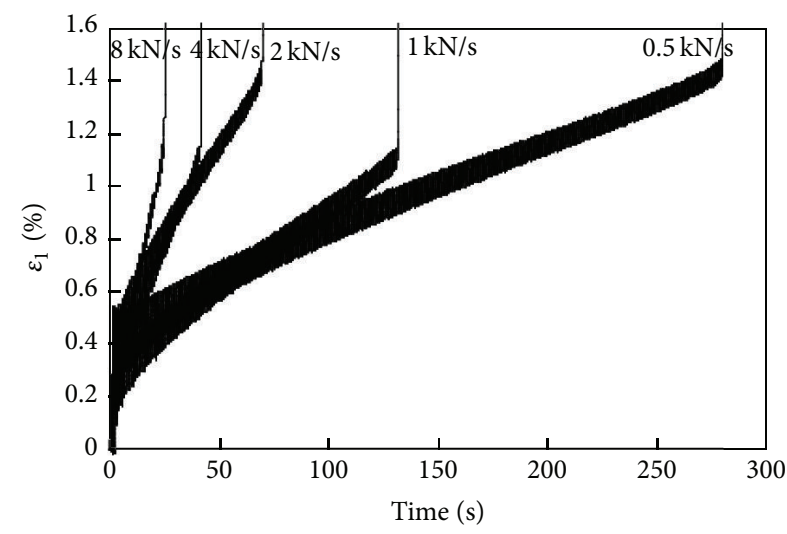

(b) Strain-time curves

FIGURE 2: Curves of stress-strain and strain-time showing effect of loading speeds.

amplitude becomes much smaller and the damage pattern resembles quasistatic compression damage, hence the fatigue life considerably rises.

3.2. Strength Properties and Fatigue Behavior of the Sandstone under Dynamic Cyclic Loading with Different Loading Frequencies. To investigate the strength properties and fatigue behavior of the sandstone under different loading frequencies, the loading amplitude and speed were up to $30 \mathrm{kN}$ and $1 \mathrm{kN} / \mathrm{s}$, respectively. The loading speeds were $0.5 \mathrm{~Hz}, 1 \mathrm{~Hz}$, $2 \mathrm{~Hz}$, and $4 \mathrm{~Hz}$. The strength and fatigue properties of the sandstone samples are shown in Table 3. The stress-strain and strain-time curves of the dynamic uniaxial cyclic loading test 


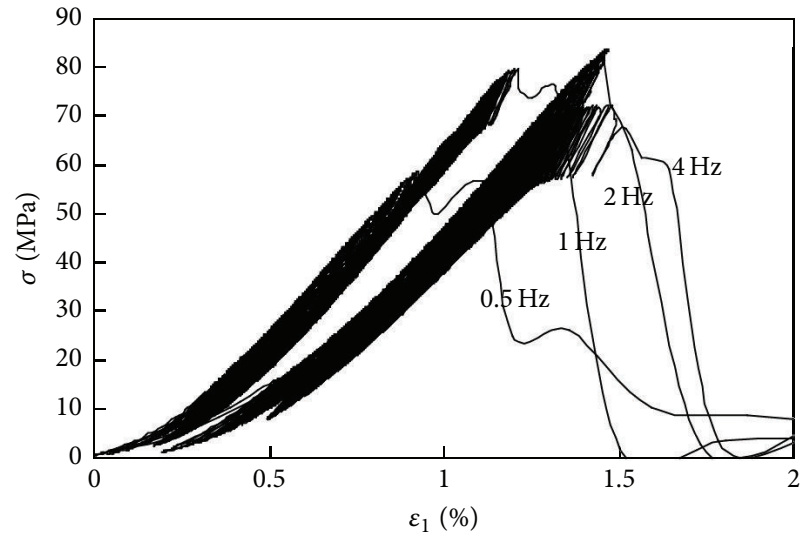

(a) Stress-strain curves

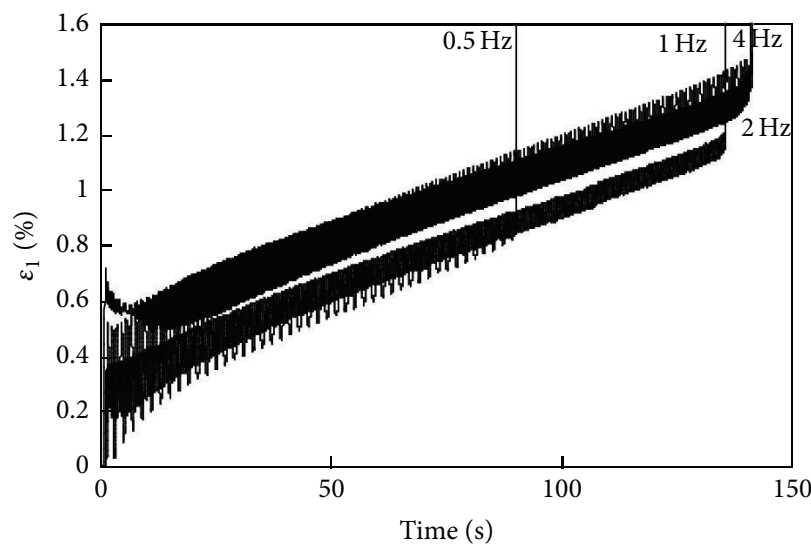

(b) Strain-time curves

FIGURE 3: Curves of stress-strain and strain-time showing effect of loading frequencies.

TABLE 3: Strength and fatigue properties of sandstone under different loading frequencies.

\begin{tabular}{lccccc}
\hline $\begin{array}{l}\text { Loading amplitude } \\
(\mathrm{kN})\end{array}$ & $\begin{array}{c}\text { Loading frequency } \\
(\mathrm{Hz})\end{array}$ & $\begin{array}{c}\text { Loading speed } \\
(\mathrm{kN} / \mathrm{s})\end{array}$ & $\begin{array}{c}\text { Peak stress } \\
(\mathrm{MPa})\end{array}$ & $\begin{array}{c}\text { Peak strain } \\
(\%)\end{array}$ & $\begin{array}{c}\text { Fatigue life } \\
(N)\end{array}$ \\
\hline 30 & 0.5 & 1 & 58.76 & 0.928 & 44 \\
30 & 1 & 1 & 83.27 & 1.468 & 139 \\
30 & 2 & 1 & 79.73 & 1.397 & 268 \\
30 & 4 & 1 & 72.07 & 1.331 \\
\hline
\end{tabular}

TABLE 4: Strength and fatigue properties of sandstone under different loading amplitudes.

\begin{tabular}{|c|c|c|c|c|c|}
\hline $\begin{array}{l}\text { Loading amplitude } \\
(\mathrm{kN})\end{array}$ & $\begin{array}{l}\text { Loading frequency } \\
(\mathrm{Hz})\end{array}$ & $\begin{array}{c}\text { Loading speed } \\
(\mathrm{kN} / \mathrm{s})\end{array}$ & $\begin{array}{c}\text { Peak stress } \\
(\mathrm{MPa})\end{array}$ & $\begin{array}{c}\text { Peak strain } \\
(\%)\end{array}$ & $\begin{array}{l}\text { Fatigue life } \\
(N)\end{array}$ \\
\hline 15 & 1 & 1 & 110.15 & 1.627 & 223 \\
\hline 30 & 1 & 1 & 88.27 & 1.467 & 132 \\
\hline 60 & 1 & 1 & 73.92 & 1.320 & 57 \\
\hline 90 & 1 & 1 & 67.15 & 1.211 & 42 \\
\hline 120 & 1 & 1 & 63.9 & 1.184 & 17 \\
\hline
\end{tabular}

under different loading frequencies are shown in Figure 3. When the loading frequency is less than $1 \mathrm{~Hz}$, the peak stress and peak strain increase with increasing loading frequency. The different case happens on the opposite condition where the peak stress and peak strain decrease with the change in loading frequency. A reason for the drop in peak stress and peak strain could be that at a higher loading frequency crack propagation may not be allowed to develop; thus, the sandstone became harder and was capable of sustaining load until final failure. Moreover, the fatigue life of the sandstone shows an increasing trend with loading frequency.

\subsection{Strength Properties and Fatigue Behavior of the Sandstone} under Dynamic Cyclic Loading with Different Loading Amplitudes. To investigate the strength properties and fatigue behavior of sandstone under different loading amplitudes, the loading frequency and speed were up to $1 \mathrm{~Hz}$ and $1 \mathrm{kN} / \mathrm{s}$, respectively. The loading amplitudes were $15 \mathrm{kN}, 30 \mathrm{kN}$,
$60 \mathrm{kN}, 90 \mathrm{kN}$, and $120 \mathrm{kN}$. The stress-strain, peak stress of cycles, peak strain of cycles, and peak strain of cycles-time curves of the dynamic uniaxial cyclic loading test under different loading amplitudes are shown in Figure 4. The sandstone sample tests conducted under different loading amplitudes showed that the peak stress, peak strain, and fatigue decrease with loading amplitudes. The strength and fatigue properties of the sandstone samples are shown in Table 4. This may be due to enhancement in the crack propagation of the sandstone. Thus, as the loading amplitude increases, the damage of salt rock is enhanced.

\section{Discussion}

Our results show that the fatigue life of sandstone varies considerably with different loading speeds, frequencies, and amplitudes. The fatigue life changes notably with the change in loading speed, frequency, and amplitude. This may be caused by the smaller external loading speed and amplitude 

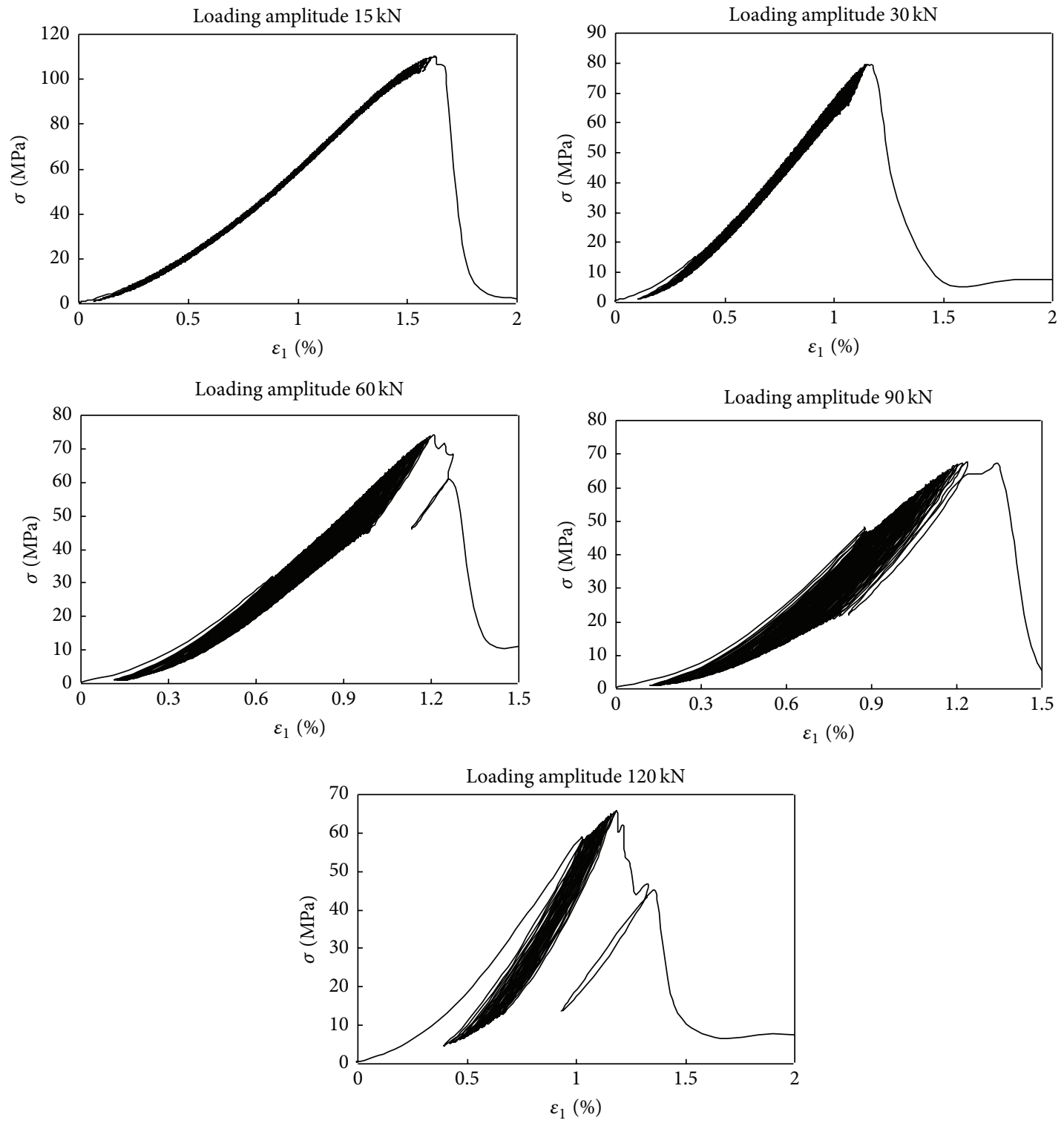

(a) Curves of stress-strain under different loading amplitudes

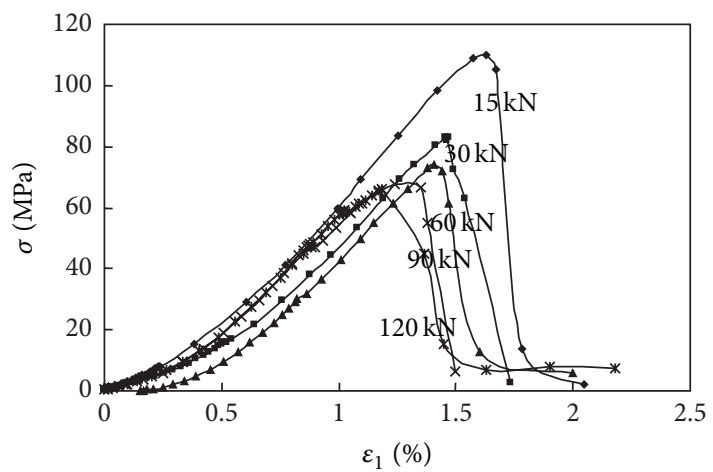

(b) Peak stress of cycles-peak strain of cycles curves

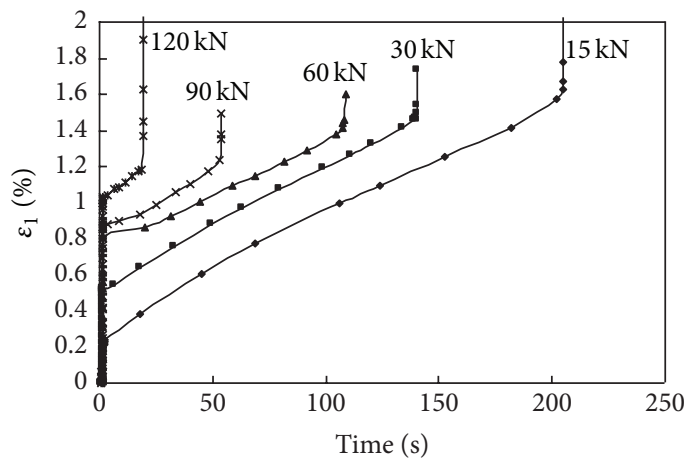

(c) Peak strain of cycles-time curves

FiguRE 4: Curves of stress-strain, peak stress of cycles-peak strain of cycles, and peak strain of cycles-time showing effect of loading amplitudes. 


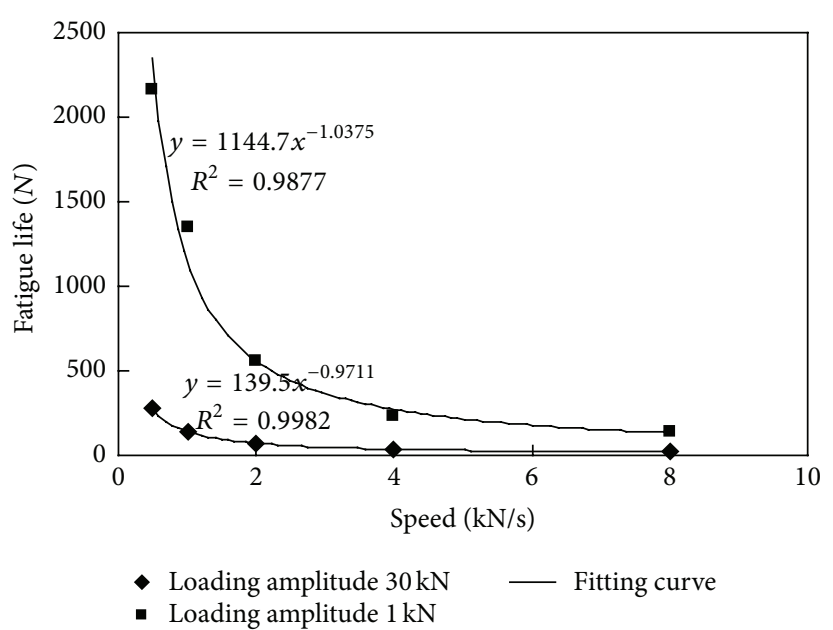

(a) Fatigue life: speed curves

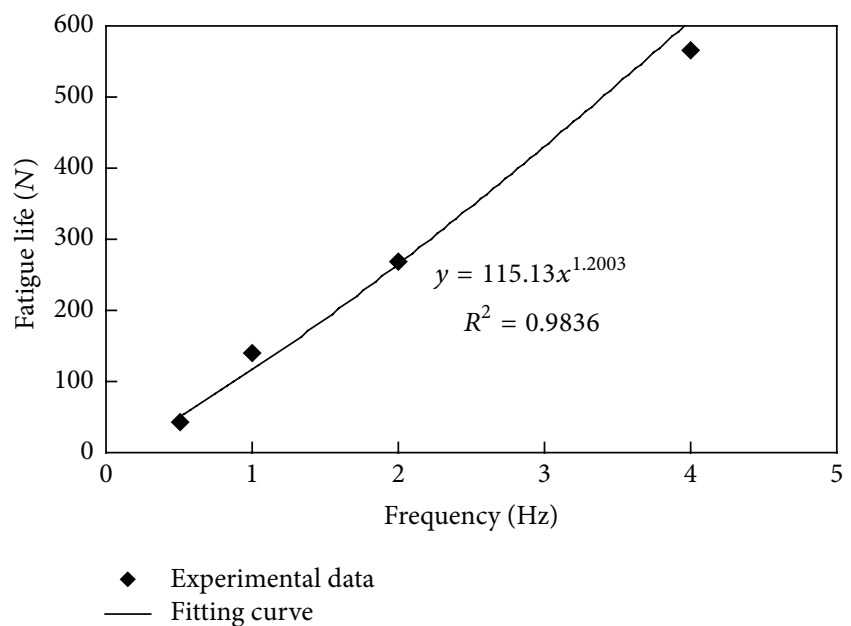

(b) Fatigue life: frequency curve

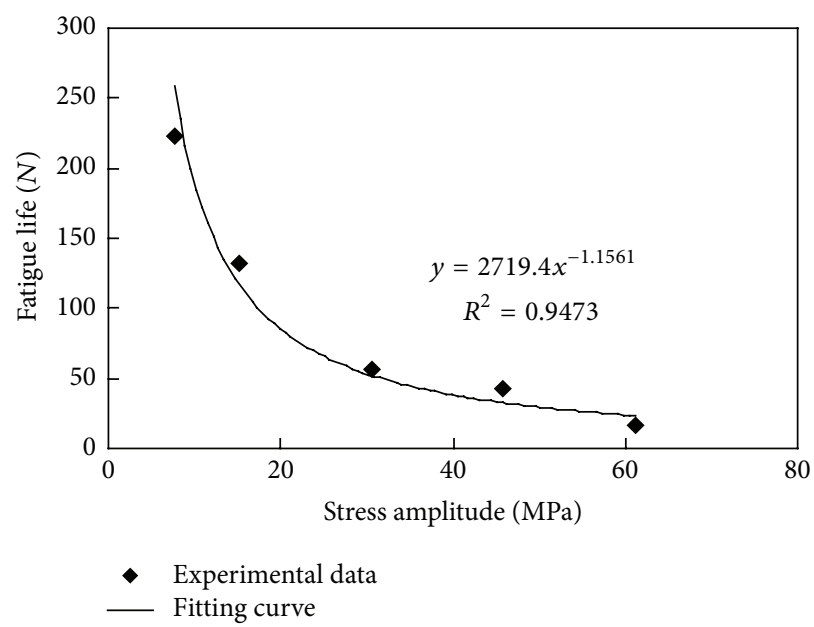

(c) Fatigue life: stress amplitude curve

FIGURE 5: Fatigue life of sandstone under different speeds, frequencies, and stress amplitudes.

in each cycle causing less damage and slowing the crack propagation process.

A stress life curve is one of the basic data for describing the fatigue properties of materials, which can be expressed in a form of table or by functions, abbreviated as $S-N$ curve. The fatigue behavior is generally described by the $S-N$ curve that shows the stress amplitude, loading speed, and frequency versus number of cycles to failure (Figure 5). The relationship between the fatigue life and loading speed and frequency and stress amplitude under dynamic cyclic loading can be expressed as

$$
N=a X^{-b}
$$

where $N$ is fatigue life, $X$ is the stress amplitude, loading speed, or frequency of the dynamic cyclic loading, and $a$ and $b$ are constants. In this paper, the fitting coefficients of the curves are $0.9877,0.9982,0.9836$, and 0.9473 , which confirm the perfect fit of the $S-N$ curves of the sandstone fatigue under different loading speeds, frequencies, and stress amplitudes and show that the fatigue characteristic of the sandstone is similar to that of other materials. Equation (1) could be used to estimate the fatigue life based on loading speed, frequency, and stress amplitude.

We also performed static uniaxial compression tests of the sandstone under loading speeds of $0.5 \mathrm{kN} / \mathrm{s}, 1 \mathrm{kN} / \mathrm{s}, 2 \mathrm{kN} / \mathrm{s}$, $4 \mathrm{kN} / \mathrm{s}$, and $8 \mathrm{kN} / \mathrm{s}$, respectively. The static average compression strength $\sigma_{o}$ and peak strain $\varepsilon_{o}$ were obtained from the tests. Our results also show that the dynamic strength and deformation factor $\left(\sigma_{d} / \sigma_{o}\right.$ and $\left.\varepsilon_{d} / \varepsilon_{o}\right)$ of the sandstone vary considerably with different loading speeds, frequencies, and amplitudes. The dynamic strength and deformation factor change notably with the change in loading speed, frequency, and amplitude (Figure 6). The dynamic strength and deformation factor are generally described by the $S-N$ curve which shows that the relationship between the stress amplitude and $\sigma_{d} / \sigma_{o}$ and $\varepsilon_{d} / \varepsilon_{o}$ under dynamic cyclic loading can be expressed as

$$
\frac{\sigma_{d}}{\sigma_{o}}=c X^{-d}
$$




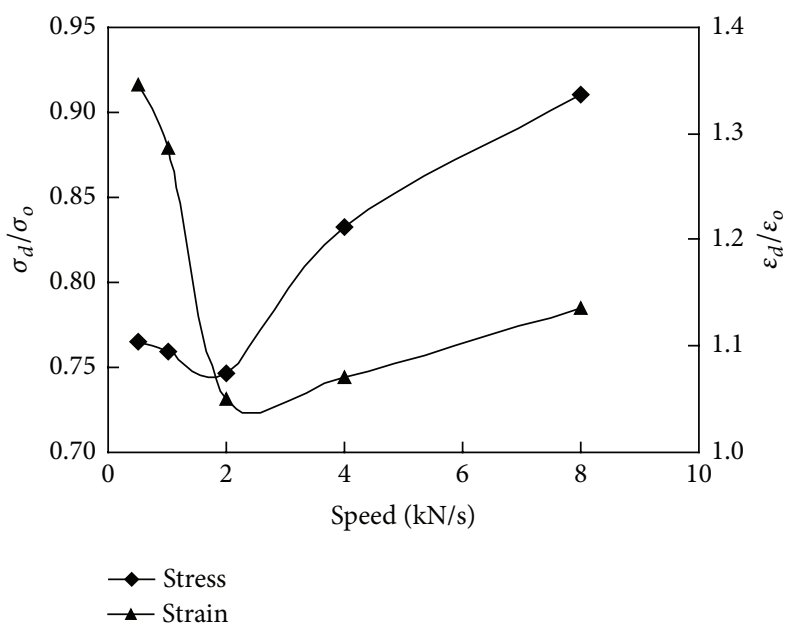

(a) $\sigma_{d} / \sigma_{o}$ and $\varepsilon_{d} / \varepsilon_{o}$ : speed curves

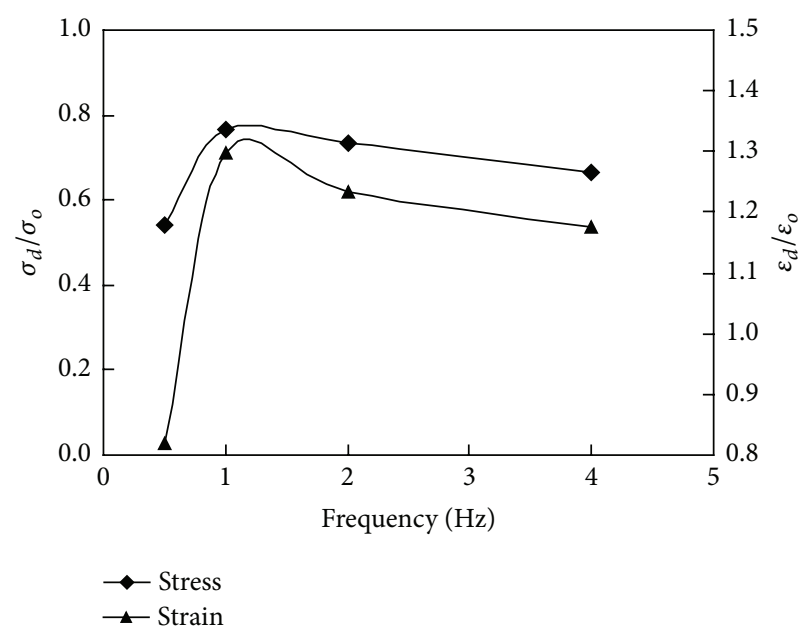

(b) $\sigma_{d} / \sigma_{o}$ and $\varepsilon_{d} / \varepsilon_{o}$ : frequency curves

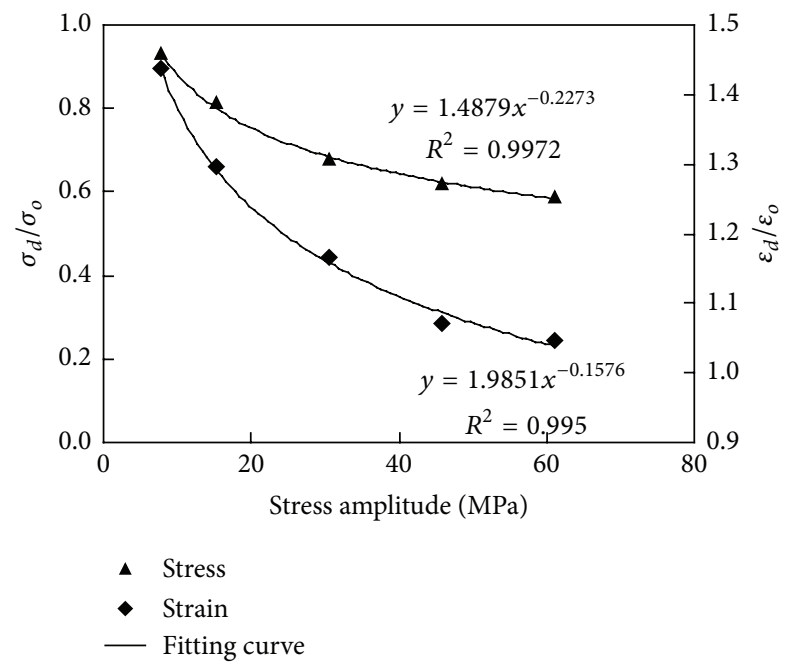

(c) $\sigma_{d} / \sigma_{o}$ and $\varepsilon_{d} / \varepsilon_{o}$ : stress amplitude curves

FiguRE 6: Strength and deformation factor under different speeds, frequencies, and stress amplitudes.

where $\sigma_{d}$ is the dynamic strength, $\sigma_{o}$ is the static compression strength, $X$ is the stress amplitude, and $c$ and $d$ are constants. In this paper, the fitting coefficients of the curves are 0.995 and 0.993 , which confirm the perfect fit of the $S-N$ curves of sandstone dynamic strength and deformation factor under different stress amplitudes.

\section{Conclusions}

In this study, we performed dynamic cyclic loading tests on sandstone to determine the fatigue life and dynamic strength under different loading speeds, frequencies, and stress amplitudes. The test results revealed that the cyclic condition affected the fatigue life as well as dynamic strength and deformation characteristics of the sandstone. It was observed that the fatigue life of the sandstone reduced with loading amplitude and speed increased, while it increased considerably with increased frequency. Based on quantitative analysis, we obtained the $S-N$ curve with fitting coefficients of $0.9877,0.9982,0.9836$, and 0.9473 , which confirm the perfect fit of the $S-N$ curves of sandstone fatigue under different cyclic condition.

It was also found that as the stress amplitude increased, the peak strength and deformation decreased considerably. The relationships between the stress amplitude and the dynamic strength and deformation factor are generally described by the $S-N$ curve under dynamic cyclic loading.

Finally, it was concluded that the peak strength and deformation of sandstone would be higher at low frequency and speed than at high frequency and speed.

\section{Conflict of Interests}

The authors declare that there is no conflict of interests regarding the publication of this paper.

\section{Acknowledgments}

The authors would like to acknowledge the financial support from the Natural Science Foundation of China (Grants no. 
51179153 and no. 51308456) and Project of Scientific Research of Shanxi (Grants nos. 2013JQ7022 and 2015JM5175).

\section{References}

[1] P. B. Attewell and I. W. Farmer, "Fatigue behaviour of rock," International Journal of Rock Mechanics and Mining Sciences \& Geomechanics Abstracts, vol. 10, no. 1, pp. 1-9, 1973.

[2] S. K. Singh, "Fatigue and strain hardening behaviour of graywacke from the flagstaff formation, New South Wales," Engineering Geology, vol. 26, no. 2, pp. 171-179, 1989.

[3] S. K. Singh, "Relationship among fatigue strength, mean grain size and compressive strength of a rock," Rock Mechanics and Rock Engineering, vol. 21, no. 4, pp. 271-276, 1988.

[4] Y. M. Tien, D. H. Lee, and C. H. Juang, "Strain, pore pressure and fatigue characteristics of sandstone under various load conditions," International Journal of Rock Mechanics and Mining Sciences \& Geomechanics Abstracts, vol. 27, no. 4, pp. 283-289, 1990.

[5] G. Li, K. Moelle, and J. Lewis, "Fatigue crack growth in brittle sandstones," International Journal of Rock Mechanics and Mining Sciences \& Geomechanics Abstracts, vol. 29, no. 5, pp. 469-477, 1992.

[6] M. N. Bagde and V. Petroš, "Fatigue properties of intact sandstone samples subjected to dynamic uniaxial cyclical loading," International Journal of Rock Mechanics and Mining Sciences, vol. 42, no. 2, pp. 237-250, 2005.

[7] M. N. Bagde and V. Petroš, "Waveform effect on fatigue properties of intact sandstone in uniaxial cyclical loading," Rock Mechanics and Rock Engineering, vol. 38, no. 3, pp. 169-196, 2005.

[8] M. N. Bagde and V. Petroš, "The effect of machine behaviour and mechanical properties of intact sandstone under static and dynamic uniaxial cyclic loading," Rock Mechanics and Rock Engineering, vol. 38, no. 1, pp. 59-67, 2005.

[9] M. N. Bagde and V. Petroš, "Fatigue and dynamic energy behaviour of rock subjected to cyclical loading," International Journal of Rock Mechanics and Mining Sciences, vol. 46, no. 1, pp. 200-209, 2009.

[10] J. Q. Xiao, D. X. Ding, F. L. Jiang, and G. Xu, "Fatigue damage variable and evolution of rock subjected to cyclic loading," International Journal of Rock Mechanics and Mining Sciences, vol. 47, no. 3, pp. 461-468, 2010.

[11] E. Liu and S. He, "Effects of cyclic dynamic loading on the mechanical properties of intact rock samples under confining pressure conditions," Engineering Geology, vol. 125, no. 27, pp. 81-91, 2012.

[12] N. T. Burdine, "Rock failure under dynamic loading conditions," Society of Petroleum Engineers Journal, vol. 3, no. 1, pp. 1-8, 1963.

[13] T. Zhenyu and M. Haihong, "An experimental study and analysis of the behaviour of rock under cyclic loading," International Journal of Rock Mechanics and Mining Sciences \& Geomechanics Abstracts, vol. 27, no. 1, pp. 51-56, 1990.

[14] E. B. Eberhardt, Brittle rock fracture and progressive damage in uniaxial compression [Ph.D. thesis], University of Saskatchewan, Saskatoon, Saskatchewan, 1998.

[15] E. Z. Lajtai, E. J. Scott Duncan, and B. J. Carter, "The effect of strain rate on rock strength," Rock Mechanics and Rock Engineering, vol. 24, no. 2, pp. 99-109, 1991.

[16] S. K. Ray, M. Sarkar, and T. N. Singh, "Effect of cyclic loading and strain rate on the mechanical behaviour of sandstone,"
International Journal of Rock Mechanics and Mining Sciences, vol. 36, no. 4, pp. 543-549, 1999.

[17] E. T. Brown and J. A. Hudson, "Fatigue failure characteristics of some models of jointed rock," Earthquake Engineering \& Structural Dynamics, vol. 2, no. 4, pp. 379-386, 1974.

[18] G. L. Prost, "Jointing at rock contacts in cyclic loading," International Journal of Rock Mechanics and Mining Sciences \& Geomechanics Abstracts, vol. 25, no. 5, pp. 263-272, 1988.

[19] E. P. Chen and L. M. Taylor, "Fracture of brittle rock under dynamic loading conditions," in Fracture Mechanics of Ceramics, R. C. Barta, A. G. Evans, D. P. H. Hasselman, and F. F. Lange, Eds., pp. 175-186, Plenum Press, New York, NY, USA, 1986.

[20] E. P. Chen, "Dynamic brittle material response based on a continuum damage model," in Impact Waves and Fracture, R. C. Barta, A. K. Mal, and G. P. MacSithigh, Eds., pp. 21-34, American Society of Mechanical Engineers, New York, NY, USA, 1995.

[21] E. P. Chen, "Non-local effects on dynamic damage accumulation in brittle solids," International Journal for Numerical and Analytical Methods in Geomechanics, vol. 23, no. 1, pp. 1-21, 1999.

[22] N. Li, W. Chen, P. Zhang, and G. Swoboda, "The mechanical properties and a fatigue-damage model for jointed rock masses subjected to dynamic cyclical loading," International Journal of Rock Mechanics and Mining Sciences, vol. 38, no. 7, pp. 1071-1079, 2001.

[23] L. Ning, P. P. Zhang, Y. Chen, and G. Swoboda, "Fatigue properties of cracked, saturated and frozen sandstone samples under cyclic loading," International Journal of Rock Mechanics and Mining Sciences, vol. 40, no. 1, pp. 145-150, 2003. 


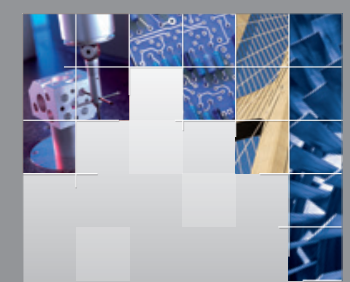

\section{Enfincering}
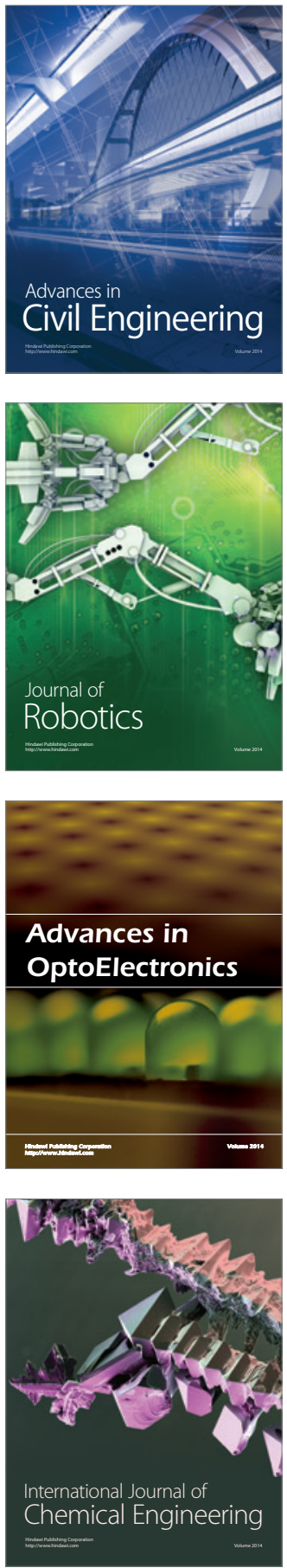

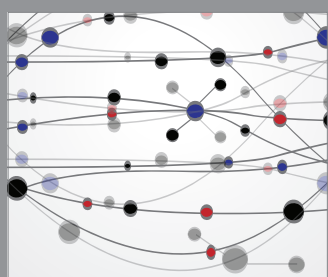

The Scientific World Journal

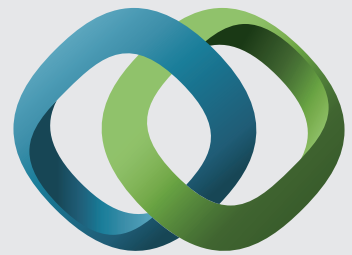

\section{Hindawi}

Submit your manuscripts at

http://www.hindawi.com
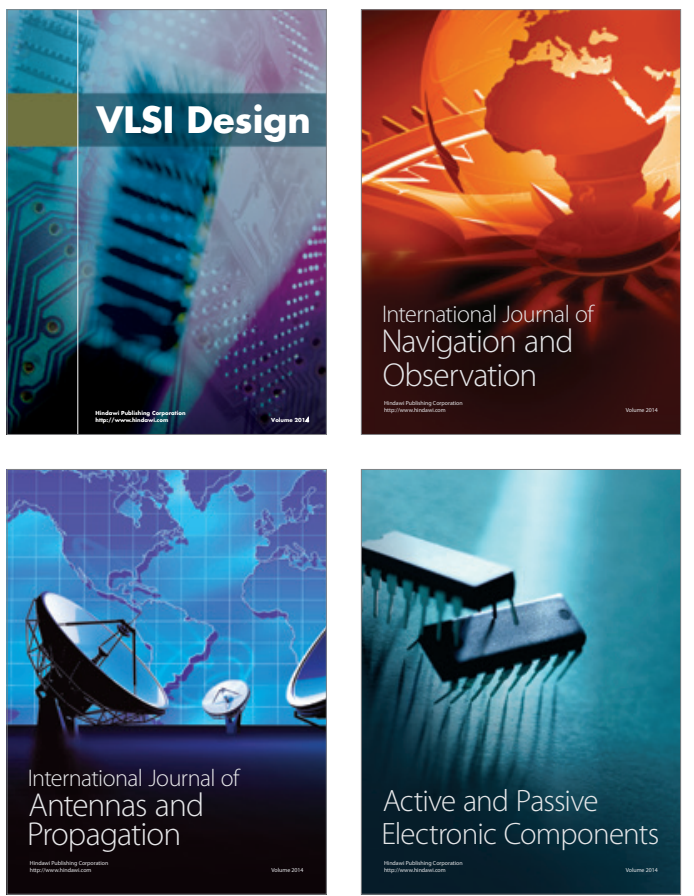
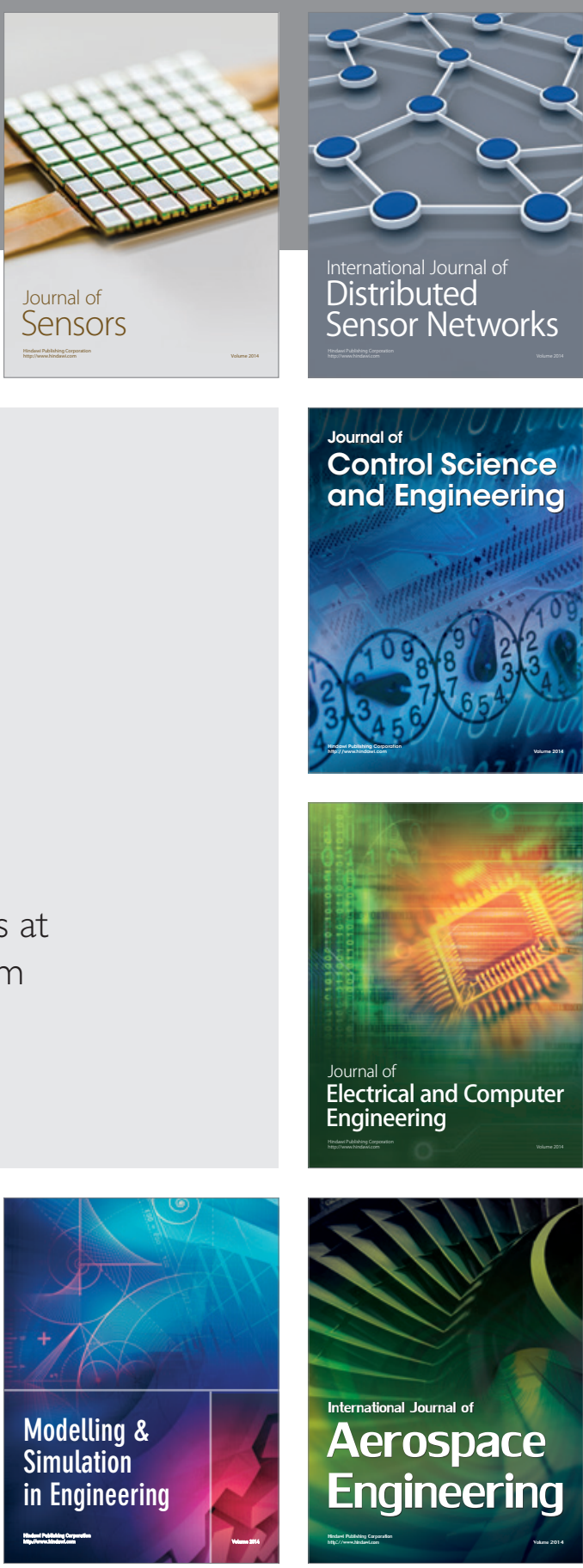

International Journal of

Distributed

Sensor Networks

Journal of

Control Science

and Engineering
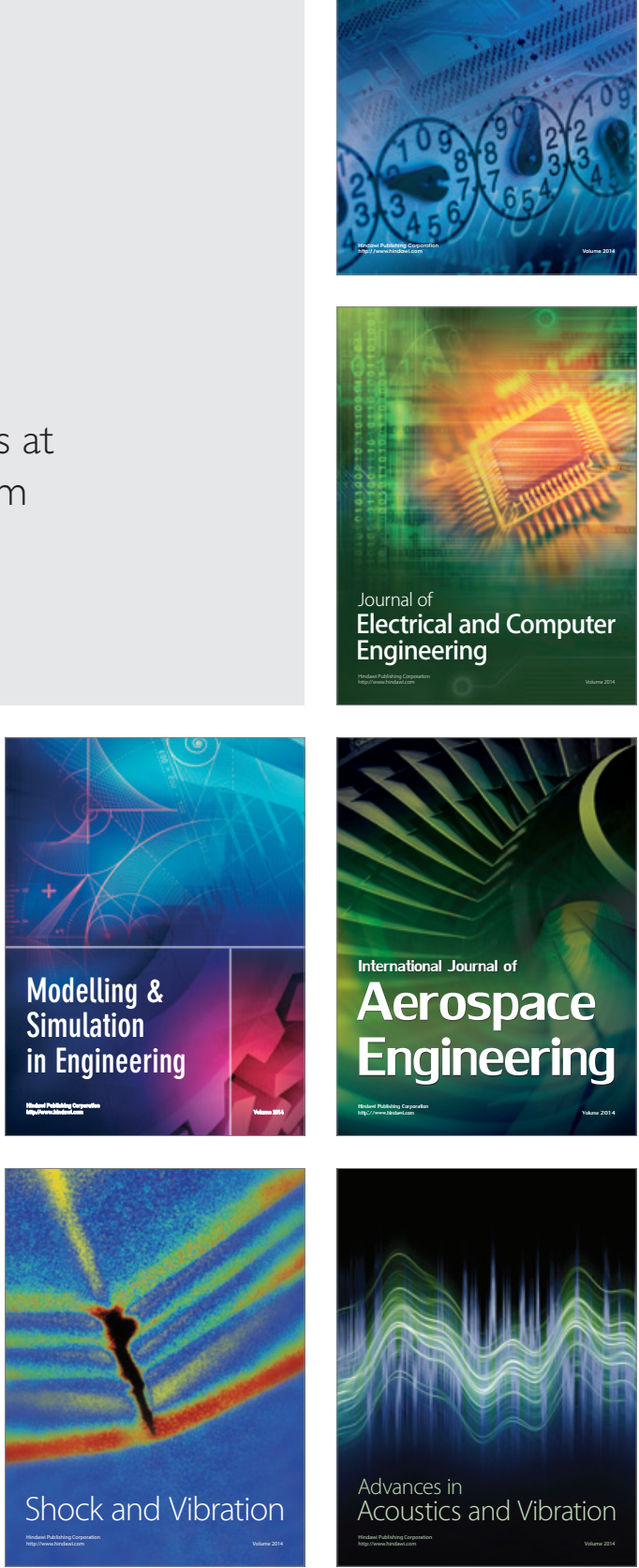